\title{
B3GnT8 plays an important role in CD147 signal transduction as an upstream modulator of MMP production in tumor cells
}

\author{
ZHI JIANG ${ }^{1 *}$, SHUIJUN HU $^{1 *}$, DONG HUA ${ }^{2 *}$, JIANLONG NI $^{1}$, LAN XU $^{1}$, YAN GE $^{3}$, \\ YINGHUI ZHOU ${ }^{1}$, ZHIHONG CHENG ${ }^{2}$ and SHILIANG WU ${ }^{1}$
}

\author{
${ }^{1}$ Department of Biochemistry and Molecular Biology, School of Medicine, Soochow University, Suzhou, Jiangsu 215123; \\ ${ }^{2}$ The Fourth People's Hospital of Wuxi, The Original Fourth Affiliated Hospital of Soochow University, Wuxi, Jiangsu 214062; \\ ${ }^{3}$ Department of Immunology, School of Medicine, Soochow University, Suzhou, Jiangsu 215123, P.R. China
}

Received March 10, 2014; Accepted June 2, 2014

DOI: $10.3892 /$ or.2014.3280

\begin{abstract}
Aberrant carbohydration by related glycosyltransferases plays an important role in the progression of cancer. This study focused on the ablity of $\beta-1,3-N$-acetylglucosaminyltransferase- 8 ( $\beta 3 \mathrm{GnT} 8)$ to regulate MMP-2 expression through regulation of the CD147 signal transduction pathway in cancer cells. $\beta 3 \mathrm{GnT} 8$ catalyzes and then extends a polylactosamine chain specifically on $\beta 1-6$-branched tetraantennary N-glycans. CD147 is a major carrier of $\beta 1-6$ branched polylactosamine sugars on tumor cells, and the high glycoform of CD147 (HG-CD147) induces matrix metalloproteinase (MMP) production. In the present study, we analyzed 33GnT8 mRNA expression in 6 cancer cell lines (MCF-7, M231, LN229, U87, SGC-7901 and U251). We found that $\beta 3$ GnT8 expression in the LN229, SGC-7901 and U251 cell lines was higher than that in the other cell lines. Therefore, we established $\beta 3 \mathrm{GnT} 8$-knockdown cell lines derived from the LN229 and SGC-7901 cell lines to examine the level of polylactosamine and CD147 N-glycosylation. In addition, tunicamycin is widely used as an inhibitor of N-linked glycosylation. Hence, various concentrations of tunicamycin were used to treat the cells in order to study its influence on CD147 $\mathrm{N}$-glycosylation and MMP-2 expression. In conclusion, we found that $\beta 3 \mathrm{GnT} 8$ regulated the level of N-glycans on CD147 and that N-glycosylation of CD147 has an important effect on MMP-2 expression. Our findings suggest that $33 \mathrm{GnT} 8$ affects the signal transduction pathway of MMP-2 by altering the N-glycan structure of CD147.
\end{abstract}

Correspondence to: Professor Shiliang Wu, Department of Biochemistry and Molecular Biology, School of Medicine, Soochow University, Suzhou, Jiangsu 215123, P.R. China

E-mail: shiliang_wu@126.com

${ }^{*}$ Contributed equally

Key words: $\beta 3 \mathrm{GnT} 8, \mathrm{CD} 147, \mathrm{MMP}-2$, polylactosamine, signal transduction pathway

\section{Introduction}

Glycosylation is one of the most common post-translational modifications. Many previous studies have concluded that aberrant glycosylation of cell surface glycoproteins is associated with the invasive and metastatic behavior of tumor cells (1). These oligosaccharides are synthesized by the sequential action of glycosyltransferases localized in the endoplasmic reticulum (ER) and Golgi apparatus. $\beta-1,3-N$ acetylglucosaminyltransferase-8 ( $\beta 3 \mathrm{GnT} 8)$, a member of the $\beta 3 \mathrm{GnT}$ family, is involved in the biosynthesis of polylactosamine chains on $\beta 1-6$-branched $\mathrm{N}$-glycans in vitro (2-4). It transfers GlcNAc to the tetraantennary non-reducing terminus of $\mathrm{N}$-glycans to form a polylactosamine structure in vitro (Fig. 1). Polylactosamine comprises repeated (Gal $\beta 1$ 4GlcNAc $\beta 1-3) n$, and attaches to O-glycans, N-glycans or glycolipids. Polylactosamine is often modified to carry important carbohydrate structures such as Lewis-related antigens (5-7) and the HNK-1 antigen (8), and has many major roles in physiological functions.

Previous research in our laboratory confirmed the ability of $\beta 3 \mathrm{GnT} 8$ to modulate matrix metalloproteinase-2 (MMP-2) in AGS gastric cancer cells and elucidated the related mechanisms (9). We found that siRNA-mediated suppression of $\beta 3 \mathrm{GnT} 8$ directly reduced MMP-2 expression and activity as assessed by RT-PCR, western blotting and gelatin zymography. Moreover, a cell invasion assay using Matrigel-coated Transwell inserts showed that the invasive ability was greatly suppressed in $\beta 3 \mathrm{GnT} 8$ siRNA-transfected cells. Furthermore, cells overexpressing the $\beta 3 \mathrm{GnT} 8$ gene (when transfected with the pEGFP-C1- $\beta 3$ GnT8 plasmid) exhibited upregulated MMP-2 gene expression, and the invasive ability of these cells was also enhanced. Protein-protein interaction analysis using the STRING database showed that $\beta 3$ GnT8 and MMP-2 may have a related signaling pathway. Therefore, our results may reveal a new mechanism by which $\beta 3 \mathrm{GnT} 8$ can regulate MMP-2 expression to affect tumor progression (9). However, MMP-2 is not a glycoprotein. Thus, we hypothesized that $\beta 3 \mathrm{GnT} 8$ affects cellular signal transduction by altering the glycan structure of various glycoproteins on the cell surface, which further influences expression of MMP-2. This detailed signal transduction pathway is yet unknown. 


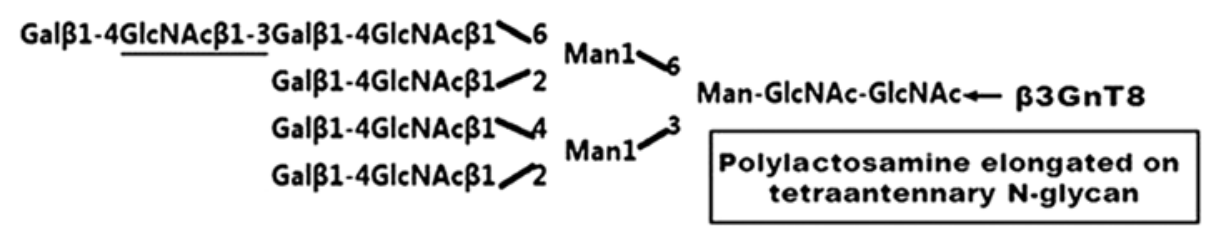

Figure 1. $\beta 3 \mathrm{GnT} 8$ is clearly responsible for polylactosamine synthesis.

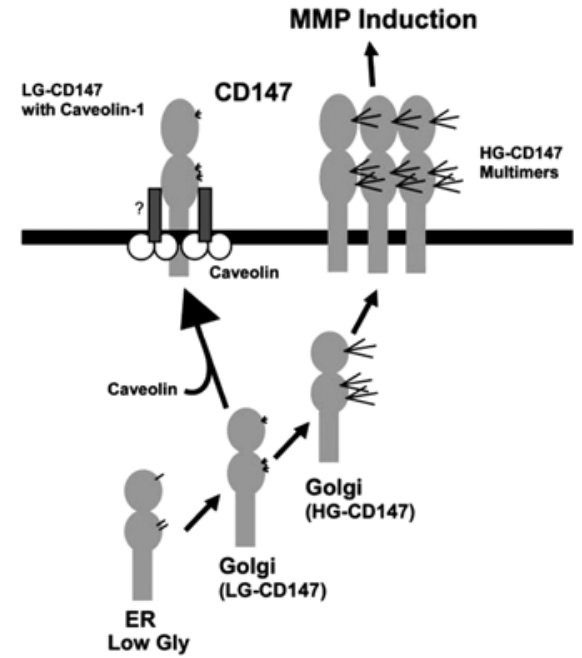

Figure 2. After CD147 enters the Golgi complex, it can mature via two possible pathways to produce the low glycoform of CD147 (LG-CD147) or the high glycoform of CD147 (HG-CD147). ER, endoplasmic reticulum.

The molecule CD147 (basigin/EMMPRIN, extracellular matrix metalloproteinase inducer) is a cell surface transmembrane glycoprotein which is highly expressed in tumor cells (10-12). CD147 consists of two immunoglobulin domains in the extracellular region: a single transmembrane domain and a short cytoplasmic domain containing 39 aa. The extracellular region of CD147 contains three Asn glycosylation sites, and the $\mathrm{N}$-glycosylation sites make similar contributions to both high and low glycoforms of CD147 (HG-CD147 and LG-CD147). The different glycosylation pattern of the native 28 -kDa protein accounts for its variable molecular weight, ranging between 44 and $66 \mathrm{kDa}(10)$. HG-CD147 ( 40-60 kDa) contains a complex-type carbohydrate, and LG-CD147 $(\sim 32 \mathrm{kDa})$ contains the mannose form. It is well known that the carbohydrate side chain is then processed in the ER and Golgi network to produce a mature glycoprotein that is exported through the secretory machinery to the plasma membrane (13). After CD147 enters the Golgi complex, it can mature via two possible pathways $(11,14,15)$. Previous studies have confirmed that modulation of CD147 is associated with the expression of MMPs in normal or tumor tissues $(16,17)$. This suggests that this CD147-mediated MMP induction could be a common mechanism in physiological or pathological situations. Many studies have confirmed that CD147 induces MMP expression via Rac1-mediated PI3K/Akt/IKK-dependent IкB- $\alpha$ degradation and NF- $\mathrm{KB}$ activation, and by MKK $7 / \mathrm{JNK}$-dependent AP-1 activation $(14,18,19)$. It has also been confirmed that only the high glycosylated CD147, except purified deglycosyl- ated CD147 and LG-CD147, determines MMP stimulatory activity $(11,12,17,20)$ (Fig. 2). Moreover, excess HG-CD147 glycosylation is attributed to $\beta 1-6$-branched $\mathrm{N}$-glycan to form polylactosamine content.

$\beta 3 \mathrm{GnT} 8$ catalyzes and then extends a polylactosamine chain specifically on $\beta 1$-6-branched tetra-antennary $\mathrm{N}$-glycans $(15,21)$. It has been cloned and characterized by us and other groups $(3,22)$. In the present study, we designed a series of experiments to investigate whether $\beta 3 \mathrm{GnT} 8$ plays an important role in CD147 signal transduction as an upstream modulator of MMP production in tumor cells.

\section{Materials and methods}

Materials. The human glioma cell lines U251, LN229 and U87; human breast adenocarcinoma cell lines MCF and M231 and human gastric cancer cell line AGS were obtained from the American Type Culture Collection (ATCC; Rockville, MD, USA). The human gastric cancer cell line SGC-7901 was obtained from the Institute of Biochemistry and Cell Biology, Chinese Academy of Science. Anti-human $33 \mathrm{GnT} 8$ polyclonal antibody was produced from rabbits in our laboratory. Anti-CD147 polyclonal and anti- $\beta$-actin antibodies were purchased from Santa Cruz Biotechnology. Anti-rabbit-HRP, anti-goat-HRP and anti-mouse-HRP secondary antibodies were purchased from Beyotime. Lycopersicon esculentum (tomato; LEA) and phycoerythrin streptavidin were purchased from Sigma-Aldrich. Other reagents were commercially available in China.

Cell culture. The human glioma cell lines U251, LN229 and U87 were cultured in Dulbecco's modified Eagle's medium (DMEM, high glucose; Gibco-BRL) supplemented with $10 \%$ fetal bovine serum (FBS). The human gastric cancer SGC7901 cell line and human breast adenocarcinoma MCF and M231 cell lines were cultured in RPMI-1640 medium supplemented with $10 \%$ FBS. All cell lines were cultured in a humidified atmosphere with $5 \% \mathrm{CO}_{2}$ at $37^{\circ} \mathrm{C}$.

Semi-quantitative reverse transcription-polymerase chain reaction $(R T-P C R)$. Total-RNA was extracted from the various cancer cell lines described above, using TRIzol (Gibco-BRL), according to the manufacturer's instructions. Complementary DNA (cDNA) was generated from total-RNA using M-MLV reverse transcriptase (MBI, Fermentas, Lithuania). The PCR conditions were as follows: initial denaturing at $95^{\circ} \mathrm{C}$ for $5 \mathrm{~min}, 30$ cycles of denaturing at $95^{\circ} \mathrm{C}$ for $30 \mathrm{sec}$, annealing at $60^{\circ} \mathrm{C}$ for $45 \mathrm{sec}$, elongation at $72^{\circ} \mathrm{C}$ for $1 \mathrm{~min}$, and finally at $72^{\circ} \mathrm{C}$ for $10 \mathrm{~min}$. The annealing temperature for $\beta 3 \mathrm{GnT} 8$ was $60^{\circ} \mathrm{C}$; for MMP- $2,55^{\circ} \mathrm{C}$ and for $\beta$-actin, $53^{\circ} \mathrm{C}$. 
Specific primers (Invitrogen) used for the genes and the expected product sizes were as follows: 5'-GGCCTGACCTA GACTCACTAGTG-3' (sense) and 5'-CGCAGTGCGGTCT GCTGGCCAG-3' (antisense) for $\beta 3 \mathrm{GnT} 8$ (518 bp); 5'-AACC CTCAGAGCCACCCCTA-3' (sense) and 5'-GTGCATACAAA GCAAACTGC-3' (antisense) for MMP-2 (286 bp); 5'-GAG CTACGAGCTGCCTGACG-3' (sense) and 5'-CCTAGAAGC ATTTGCGGTGG-3' (antisense) for $\beta$-actin (416 bp). The PCR products were separated by electrophoresis on $10 \mathrm{~g} / \mathrm{l}$ agarose gel and visualized by ethidium bromide staining.

Lipofectamine-mediated cell transfection. Cells (LN229, SGC-7901, U251) were seeded in a 6-well plate at a density of $60-70 \%$. After $12 \mathrm{~h}$, they were transfected with pSilencircle- $\beta 3$ GnT8Scr and pSilencircle- $\beta 3$ GnT8Si using Lipofectamine $^{\mathrm{TM}} 2000$ transfection reagent according to the manufacturer's protocol, followed by selection with G418 $(500 \mu \mathrm{g} / \mathrm{ml})$. Additionally, untransfected cells served as the control. The stable cells were correspondingly named T8Scr and $\mathrm{T} 8 \mathrm{Si}$, and untransfected cells were named $\mathrm{NC}$.

Western blot analysis. Western blot analysis was conducted using standard methods. Protein was extracted from the cell lysates using ice-cold radioimmunoprecipitation assay (RIPA) lysis buffer (50 mM Tris pH 7.4, $150 \mathrm{mM} \mathrm{NaCl}, 1 \%$ NP-40, $0.5 \%$ sodium deoxycholate, $0.1 \%$ SDS, sodium orthovanadate, sodium fluoride, EDTA and leupeptin) supplemented with $1 \mathrm{mM}$ PMSF. The protein concentration in the cell lysates was determined using a protein assay kit (KeyGEN Biotech, China). An equal amount of protein from each sample was mixed with 4X loading buffer (250 mM Tris-HCl, $40 \%$ glycerol, $5 \%$ SDS, $0.005 \%$ bromophenol blue and $100 \mathrm{mM}$ DTT) and denatured for $5 \mathrm{~min}$ at $100^{\circ} \mathrm{C}$. Total proteins were then separated by SDS/polyacrylamide gel electrophoresis (10\% acrylamide gel) and transferred onto polyvinylidene fluoride (PVDF) membranes that had been pretreated with methanol. The membranes were blocked for $1 \mathrm{~h}$ at room temperature in PBS-T (PBS with $0.05 \%$ Tween-20 ${ }^{\mathrm{TM}}$ ) containing 5\% skim milk. The proteins were analyzed using specific antibodies as indicated. Blots were incubated overnight at $4^{\circ} \mathrm{C}$ with the primary antibodies against $\beta 3 \mathrm{GnT} 8$ (1:400), CD147 (1:300) and $\beta$-actin $(1: 1,000)$. After removal of the primary antibody, the blots were incubated for $1 \mathrm{~h}$ at room temperature with goat anti-rabbit, donkey anti-goat, rabbit anti-mouse $\operatorname{IgG}(1: 1,000)$ horseradish peroxidase (HRP)-conjugated secondary antibodies. For detection, enhanced chemiluminescence was used according to the manufacturer's instructions (ECL Plus Detection System, Beyotime).

Flow cytometry. To detect the presence or absence of certain carbohydrate determinants, the stable cells (LN229 and SGC-7901) and NC, T8Scr and T8Si cells were stained with plant lectin and analyzed by flow cytometry (FACScan; BD Biosciences). Approximately $5 \times 10^{5}$ cells were incubated for $2 \mathrm{~h}$ at room temperature in $500 \mu \mathrm{l}$ of assay buffer $(10 \mathrm{mM}$ HEPES, $0.15 \mathrm{M} \mathrm{NaCl}, 0.08 \% \mathrm{NaN}_{3}, 0.1 \mathrm{mM} \mathrm{CaCl}_{2}$ and $1 \%$ BSA pH 7.5) containing biotinylated lectin (Sigma-Aldrich) and LEA lectin $(20 \mu \mathrm{g} / \mathrm{ml})$. Lectin-stained cells were washed with TPBS (PBS $+0.05 \%$ Tween-20) and incubated with streptavidin-R-phycoerythrin ( $0.4 \mu \mathrm{g} / \mathrm{ml}$; Sigma-Aldrich) for
$1 \mathrm{~h}$ at room temperature in $500 \mu \mathrm{l}$ of assay buffer $(0.01 \mathrm{M}$ phosphate-buffered saline $\mathrm{pH} 7.4,1 \%$ BSA and $15 \mathrm{mM}$ sodium azide). The cell suspensions were washed in TPBS in $300 \mu \mathrm{l}$ PBS containing $1 \%$ BSA and analyzed for fluorescent intensity by flow cytometry.

Immunofluorescent staining. Expression of certain carbohydrate determinants was determined by fluorescence microscopy. The stable cells LN229, NC, T8Scr and T8Si were fixed with $4 \%$ paraformaldehyde for $30 \mathrm{~min}$ at room temperature, followed by permeabilization with $0.2 \%$ Triton $\mathrm{X}-100$ in PBS and blocking of non-specific binding with Carbo-Free ${ }^{\mathrm{TM}}$ blocking solution (Vector) for $30 \mathrm{~min}$ at room temperature. Biotinylated LEA lectin $(20 \mu \mathrm{g} / \mathrm{ml})$ in assay buffer (10 mM HEPES, $0.15 \mathrm{M} \mathrm{NaCl}, 0.08 \% \mathrm{NaN}_{3}, 0.1 \mathrm{mM}$ $\mathrm{CaCl}_{2}, 1 \%$ BSA pH 7.5) was applied to the LN229 cells and incubated for $2 \mathrm{~h}$ at room temperature. After being washed with TPBS (PBS + 0.05\% Tween-20), the LN229 cells were incubated with Streptavidin-R-phycoerythrin $(0.4 \mu \mathrm{g} / \mathrm{ml})$ for $1 \mathrm{~h}$ at room temperature in assay buffer (0.01 M PBS pH 7.4, $1 \%$ BSA and $15 \mathrm{mM}$ sodium azide). After being washed with TPBS, images were obtained using an inverted fluorescence microscope combined with a digital camera.

Regulation of CD147 glycosylation and MMP-2 expression by tunicamycin. Briefly, in vitro, the cells (SGC-7901 and U251) were seeded in 6-well plate and pre-incubated overnight. The cells were washed once with PBS and cultured for $24 \mathrm{~h}$ in fresh culture media in the absence or presence of tunicamycin in a dose-dependent manner $(0,2.5,5 \mu \mathrm{g} / \mathrm{ml})$. The cells were harvested, and CD147 and MMP-2 expression was determined by western blotting and RT-PCR analysis.

Analysis of protein-protein interaction (PPI) networks of CDI47 and MMPs using the STRING database. STRING is a database of known and predicted protein interactions. The interactions include direct (physical) and indirect (functional) associations. They are derived from four sources: genomic context, high-throughput experiments, coexpression (conserved) and previous knowledge. STRING quantitatively integrates interaction data from these sources for a large number of organisms, and transfers the information between these organisms where applicable. The database currently covers 5,214,234 proteins from 1,133 organisms. We set out to study the PPI network derived from an analysis of the STRING database showing that CD147 and MMPs have a related signaling pathway.

Statistical analyses. Statistical analysis was performed using SPSS 13.0 software $^{\circledast}$. Results are expressed as mean \pm SD. Statistical significance was evaluated for data from three independent experiments using the Student's t-test. $P<0.05$ was considered to indicate a statistically significant difference.

\section{Results}

B3GnT8 mRNA expression in 6 cancer cell lines (MCF-7, M231, LN229, U87, SGC-7901 and U251). As shown in Fig. 3A, the $33 \mathrm{GnT} 8 \mathrm{mRNA}$ expression level in the LN229, SGC-7901 and U251 cells was higher than that in the other cell 
A
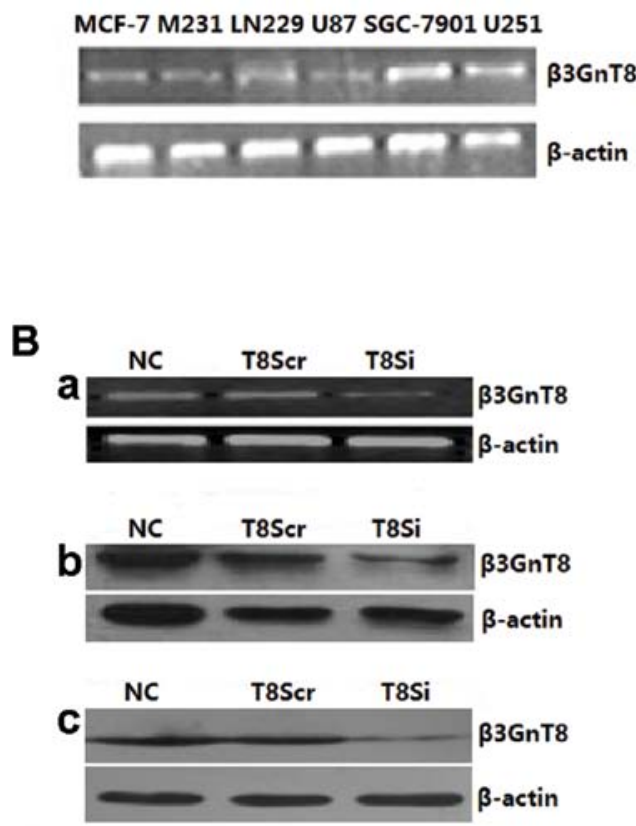
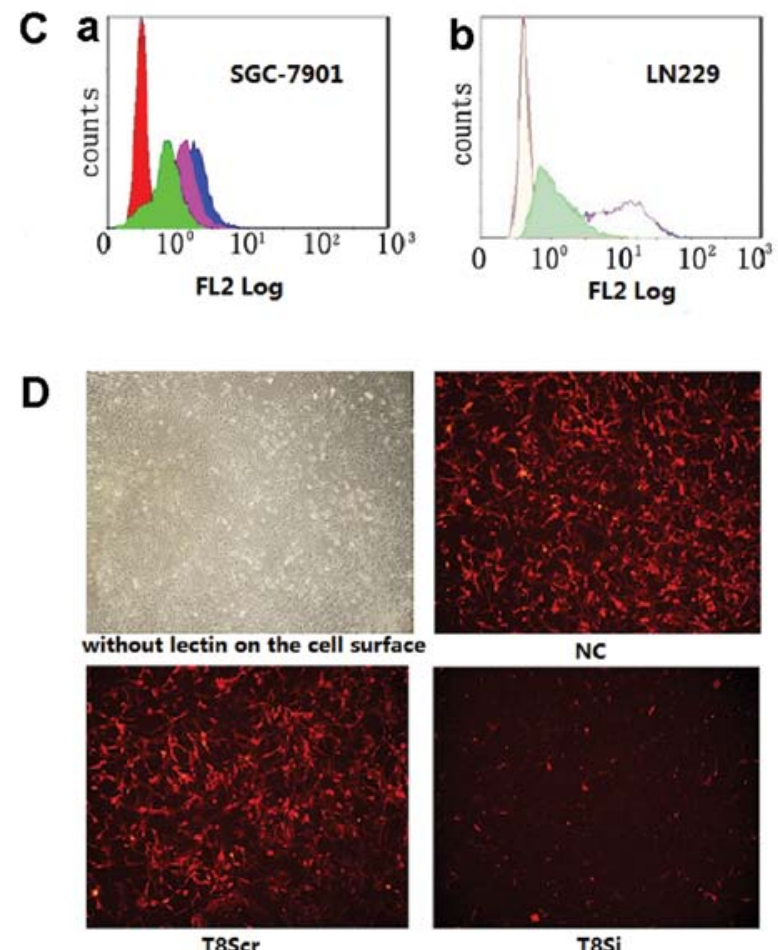

Figure 3. $\beta 3 \mathrm{GnT} 8$ is involved in the biosynthesis of polylactosamine chains. (A) $\beta 3 \mathrm{GnT} 8 \mathrm{mRNA}$ expression level in the 6 cancer cell lines. (B) $\beta 3 \mathrm{GnT} 8$ knockdown in the SGC-7901 and LN229 cell lines. (a) RT-PCR of $\beta 3$ GnT8 in the transfected SGC-7901 cell line. (b) Western blot analysis of $\beta 3$ GnT8 in the transfected SGC-7901 cell line. (c) Western blot analysis of $\beta 3$ GnT8 in the transfected LN229 cell line. (C) Flow cytometric analysis of SGC-7901 and LN229 cells transfected with the $33 \mathrm{GnT} 8-k n o c k d o w n$ gene. (a) SGC-7901 cells: red region, without lectin on the cell surface; deep blue region, NC; purple-red region, T8Scr; green region, T8 Si. (b) LN229 cells: first white region, without lectin on the cell surface; second white region, NC; purple region, T8Scr; grayblue region, T8Si. (D) Immunofluorescent staining analysis of the LN229 cells tansfected with the $\beta 3 \mathrm{GnT} 8$ siRNA gene. The experiments are representative of three independent experiments with similar results.

lines. Hence, these three cell lines with high $\beta 3 \mathrm{GnT} 8$ expression were chosen to study the relationship between $\beta 3 \mathrm{GnT} 8$ and CD147 glycosylation.

Establishment of $\beta 3 G n T 8$ downregulation in SGC-7901 and LN229 cells. To investigate whether $\beta 3 \mathrm{GnT} 8$ plays an important role in the CD147 signal transduction pathway as an upstream modulator of MMP production in tumor cells, we constructed two $\beta 3 \mathrm{GnT} 8$-knockdown cell lines derived from SGC-7901 and LN229 cells, and measured the mRNA and protein expression levels by RT-PCR and western blotting, respectively. As shown in Fig. 3B-a, the $\beta 3 \mathrm{GnT} 8$ transcripts were decreased in the T8Si SGC-7901 cells when compared with its control groups $(\mathrm{P}<0.05)$. Similar to the RT-PCR results, the $\beta 3 \mathrm{GnT} 8$ protein was markedly reduced in the T8Si SGC-7901 and T8Si LN229 cell lines (Fig. 3B-b and $-\mathrm{c} ; \mathrm{P}<0.05)$. These results revealed that we successfully constructed two $\beta 3 \mathrm{GnT}$ 8-knockdown cell lines derived from SGC-7901 and LN229.

Biosynthesis of polylactosamine following $\beta 3$ GnT8 downregulation in the SGC-7901 and LN229 cells. To determine the enzymatic activity of $\beta 3 \mathrm{GnT} 8$ in vivo, the two constructed $\beta 3$ GnT8-knockdown cell lines, SGC-7901 and LN229, were used in this experiment. Cell surface expression of carbohydrate chains were detected by flow cytometric analysis and immunofluorescent staining using LEA lectin, which can recognize the polylactosamine chain of $\mathrm{N}$-glycans. As shown in
Fig. $3 \mathrm{C}$, compared with the $\beta 3 \mathrm{GnT} 8 \mathrm{Scr}$ transfectants and NC, the $\beta 3$ GnT8Si transfectants of SGC-7901 and LN229 exhibited reduced levels of LEA lectin $(\mathrm{P}<0.05)$. Immunofluorescent staining was performed to observe the alteration of carbohydrate chains in the LN229 cells. Similar to the results of the flow cytometric analysis, the fluorescence intensity of the T8Si cell groups was apparently weaker when compared with the Scr and NC transfectants when incubated with LEA lectin against polylactosamine (Fig. 3D, $\mathrm{P}<0.05)$. These results indicate that $\beta 3 \mathrm{GnT}$ is involved in the biosynthesis of polylactosamine chains on the $\beta 1-6$-branched N-glycans.

$\beta 3 G n T 8$ regulates $C D 147$ glycosylation following $\beta 3 G n T 8$ downregulation of the SGC-7901 and LN229 cells. To verify whether $\beta 3 \mathrm{GnT} 8$ regulates CD147 glycosylation, the two previously constructed SGC-7901 and LN229 cell lines with $\beta 3$ GnT8 downregulation were also tested in the experiment. As shown in Fig. 4, the T8Si SGC-7901 and T8Si LN229 cells exhibited a direct reduction in the levels of HG-CD147 protein compared with the T8Scr transfectants and NC groups $(\mathrm{P}<0.05)$.

Characterization of LG-CD147 and HG-CD147 forms in the $U 251$ and SGC-7901 cells. Western blot analysis revealed that a large amount of CD147 was highly expressed in the U251 and SGC-7901 cells as indicated by broad bands with apparent molecular weights ranging from 32 to $65 \mathrm{kDa}$, which are characteristic of CD147 polypeptides with extensive and heterogeneous glycosylation. Variability in CD147 

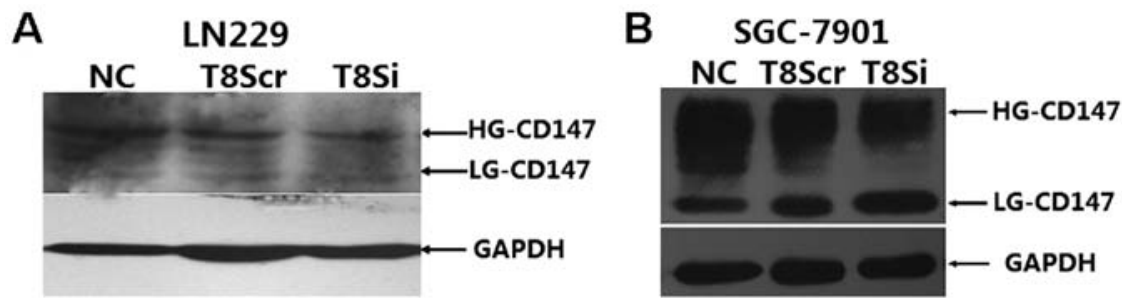

Figure 4. $\beta 3 \mathrm{GnT} 8$ regulates the glycosylation of CD147 in the transfected LN229 and SGC-7901 cells. (A) In the LN229 cells, the level of glycosylation on CD147 is shown in the NC, T8Scr and T8Si groups by western blotting. (B) In the SGC-7901 cells, the level of glycosylation on CD147 is shown in the NC, T8Scr and T8Si groups by western blotting. The experiments are representative of three independent experiments with similar results.

A

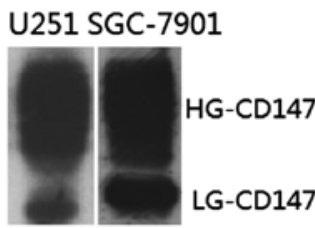

B U $\quad 251$

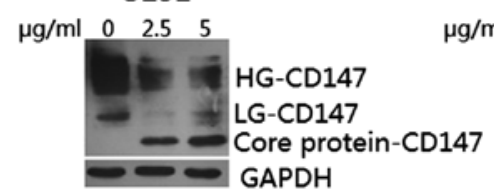

GAPDH
SGC-7901 $\mathrm{ug} / \mathrm{ml} \quad 0 \quad 2.5$
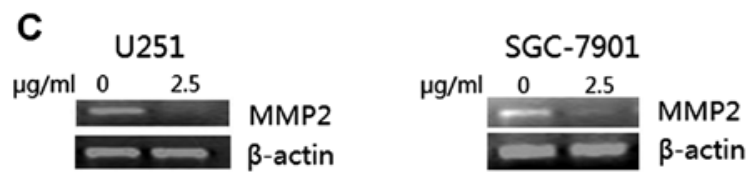

Figure 5. Analysis of the forms of HG-CD147 and LG-CD147 by western blot analysis and effect of tunicamycin on CD147 N-glycosylation and MMP-2 expression in U251 and SGC-7901 cells. (A) HG-CD147 and LG-CD147 forms as determined by western blot analysis in the U251 and SGC-7901 cells. (B) Effect of tunicamycin on CD147 N-glycosylation in the U251 and SGC-7901 cells as determined by western blot analysis. (C) Effect of tunicamycin on MMP-2 expression in the U251 and SGC-7901 cells as determined by RT-PCR. The experiments are representative of three independent experiments with similar results.

$\mathrm{N}$-glycosylation was detected (Fig. 5A). Obviously, CD147 was present in the U251 and SGC-7901 cells as a high glycosylated (HG) form migrating at $\sim 45-65 \mathrm{kDa}$ and as a low glycosylated (LG) form migrating at $\sim 32-44 \mathrm{kDa}$, depending on the glycosylation of the core protein $(27 \mathrm{kDa})$.

Effect of tunicamycin on CD147 glycosylation and MMP-2 expression in U251 and SGC-7901 cells. Western blot analysis revealed that CD147 did have two different forms: a high glycosylated (HG) form and a low glycosylated (LG) form. U251 and SGC-7901 cells were treated with various concentrations of tunicamycin, an inhibitor of N-linked glycosylation of newly synthesized proteins, for $24 \mathrm{~h}$. As shown in Fig. 5B, following tunicamycin treatment in U251 and SGC-7901 cells, a single new band of molecular weight $(27 \mathrm{kDa})$ consistent with the size of the core protein was visualized by western blotting $(\mathrm{P}<0.05)$. These results suggest that $\mathrm{N}$-linked glycosylation of CD147 was highly sensitive to the inhibition of tunicamycin.

Analysis of protein-protein interaction (PPI) networks of CD147 and MMPs. We studied the interacting neighbors of CD147 [also called basigin (BSG)] using the STRING database. As shown in Fig. 6, the analysis of protein-protein interaction (PPI) networks of CD147 and MMPs was derived from an analysis of the STRING database. The results revealed that CD147 has a related signaling pathway with MMPs including MMP-1, MMP-2, MMP-3, MMP-7, MMP-9, MMP-11 and MMP-14.

\section{Discussion}

The complex carbohydrate chains of glycoproteins (O-glycans and $\mathrm{N}$-glycans), glycolipids and proteoglycans represent secondary gene products formed through the reactions of numerous glycosyltransferases. Aberrant carbohydration by the related glycosyltransferases plays an important role in cell-cell and cell-molecular recognition, such as receptor combination, signaling pathway and molecular, which may lead to a variety of biological alterations in cells (24).

The $\beta 3 \mathrm{GnT}$ familly contains 7 members $(\beta 3 \mathrm{GnT} 2$, $\beta 3 \mathrm{GnT} 3, \beta 3 \mathrm{GnT} 4, \beta 3 \mathrm{GnT} 5, \beta 3 \mathrm{GnT} 6, \beta 3 \mathrm{GnT} 7$ and $\beta 3 \mathrm{GnT} 8)$ which are able to catalyze the initiation and elongation of polylactosamine chains. However, they exhibit a different substrate specificity dependent on the length of the polylactosamine chain $(25,26)$. All $\beta 3 \mathrm{GnTs}$, namely $\beta 3 \mathrm{GnT} 2$, $\beta 3 \mathrm{GnT} 3, \beta 3 \mathrm{GnT} 4, \beta 3 \mathrm{GnT} 5, \beta 3 \mathrm{GnT} 7$ and $\beta 3 \mathrm{GnT} 8$, except for $\beta 3 \mathrm{GnT} 6$, can transfer GlcNAc to Gal to synthesize a polylactosamine chain. However, each differs in its preference for acceptor molecules, i.e., core $1 \mathrm{O}$-glycan, glycolipids or keratan sulfate (KS). Each enzyme may have distinct roles in physiological processes. Notably, $\beta 3 \mathrm{GnT} 8$ was cloned and characterized by various groups, including ours, as being involved in the biosynthesis of polylactosamine chains on $\beta 1-6$-branched $\mathrm{N}$-glycans in vitro $(3,22)$. It has been reported that $\beta 1-6$-branched $\mathrm{N}$-glycans containing polylactosamine act on a variety of malignant phenotypes of tumor cells, affecting cell proliferation (27) and metastatic potential (28-30). 


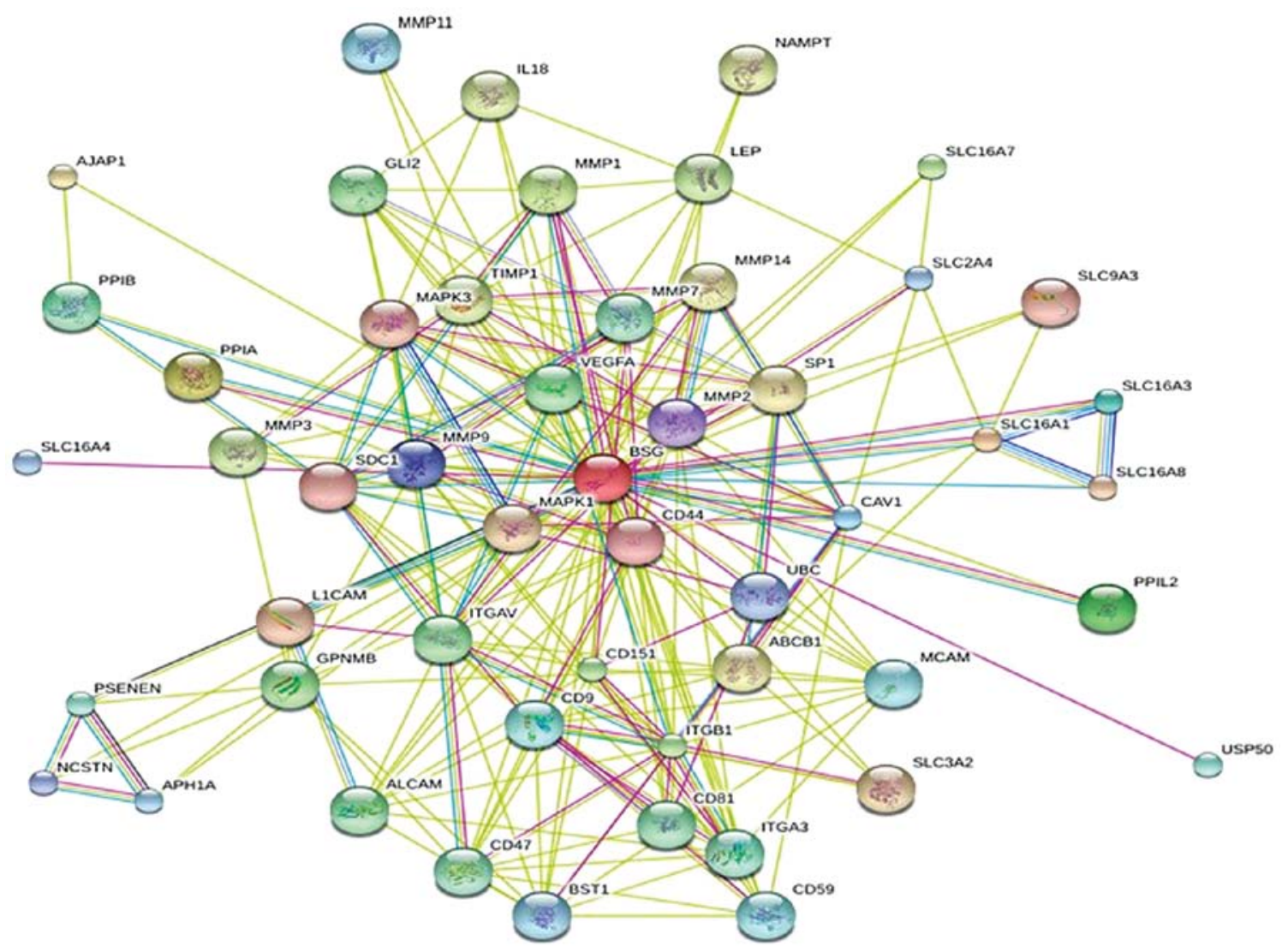

Figure 6. Analysis of protein-protein interaction (PPI) networks of CD147 [also termed basigin (BSG)] and MMPs. CD147 has a related signaling pathway with MMPs including MMP-1, MMP-2, MMP-3, MMP-7, MMP-9, MMP-11 and MMP-14 based on an analysis of the STRING database.

Previous studies have demonstrated the ability of $\beta 3 \mathrm{GnT} 8$ to modulate matrix metalloproteinase-2 (MMP-2) in AGS gastric cancer cells and the possible mechanism involved $(9,23)$. However, the detailed signal transduction pathway is still unknown. In the present study, we found that $\beta 3 \mathrm{GnT}$ \% plays an important role in the CD147 signal transduction pathway as an upstream modulator of MMP production in the tumor microenvironment. We found that $\beta 3 \mathrm{GnT} 8$ is widely expressed in several different types of cancer cell lines by RT-PCR analysis (Fig. 3A). In addition, Lipofectamine-mediated siRNA knockdown of $\beta 3 \mathrm{GnT} 8$ was successfully conducted in the LN229 and SGC-7901 cell lines for use in our further experiments (Fig. 3B). After 33 GnT8 was downregulated in LN229 and SGC-7901 cell lines, the levels of polylactosamine chains were markedly reduced, when compared with the control groups by flow cytometric analysis (Fig. 3C). Similarly, immunofluorescent staining analysis demonstrated that the cell surface polylactosamine chains of the $\beta 3 \mathrm{GnT} 8 \mathrm{Si}$ transfectants was visibly weaker when compared to the control groups (Fig. 3D). These results indicate that $\beta 3 \mathrm{GnT} 8$ is involved in the biosynthesis of polylactosamine chains. Moreover, it has been reported that glycoprotein CD147 has LG-CD147 and HG-CD147 forms $(10,16)$. Studies have confirmed that excess CD147 glycosylation is attributable to $\beta 1-6$-branches to form polylactosamine content (11). Thus, it was hypothesized that $\beta 3 \mathrm{GnT} 8$ is involved in the biosynthesis of polylactosamine chains on the HG form of CD147. To demonstrate the validity of this hypothesis, previously constructed $\beta 3 \mathrm{GnT} 8$ siRNA knockdown LN229 and SGC-7901 cell lines were used. As evident from Fig. 4 , the cells transfected with $\beta 3 \mathrm{GnT} 8$ siRNA exhibited a direct reduction in the levels of HG-CD147 protein when compared with levels in the control groups (Fig. 4A and B). In addition, a previous study showed that $\mathrm{N}$-glycosylation of CD147, particularly the $\beta 1-6$-branched N-glycans contributes to MMP-inducing activity in tumor cells (20). Tumicamycin is widely used as an inhibitor of N-linked glycosylation that blocks the initial step in glycoprotein synthesis, thus blocking the synthesis of all N-linked glycoproteins (31). Hence, various concentrations of tunicamycin were used in this experiment to study its influence on CD147 N-glycosylation and MMP-2 expression. As shown in Fig. 5A, LG-CD147 and HG-CD147 forms were detected in the U251 and SGC-7901 cell lines by western blot analysis. Following tumicamycin treatment, the levels of HG-CD147 and LG-CD147 decreased considerably, and a single new band of molecular weight, consistent with the size of the core protein-CD147, appeared, as compared with the control groups (Fig. 5B). Meanwhile, the expression of MMP-2 almost disappeared following tumicamycin treatment, when compared with the level in the control groups (Fig. 5C). This may indicate that the LG-CD147 and HG-CD147 forms are present in cancer cells, and further play a role in tumor progression, including promotion of MMP-2 expression. However, once the glycosylation part of CD147 decreased or disappeared to the core protein-CD147, it lost the function of promoting MMP-2 expression. Previous studies have shown that inhibition of N-linked glycosylation reduces Akt phosphorylation in U251 cells (13). Previously, we found that CD147 N-glycosylation regulates MMP expression through 
numerous possible pathways; one is Akt-dependent IкB- $\alpha$ degradation (14). We speculated that $\mathrm{N}$-glycosylation levels of CD147 play an important role in MMP-2 expression through Akt signal transduction. In general, from these results, we demonstrated that the level of CD147 N-glycosylation mainly contains $\beta 1$-6-branched polylactosamine, which were catalyzed by $\beta 3 \mathrm{GnT} 8$. In addition, the $\mathrm{N}$-glycans of $\mathrm{CD} 147$ are important to determine its MMP-2 stimulating expression.

In summary, the present study demonstrated that $\beta 3 \mathrm{GnT} 8$ is involved in the biosynthesis of polylactosamine, which regulates CD147 N-glycosylation and further influences MMP-2 expression in tumor cells. Therefore, we demonstrated that $\beta 3 \mathrm{GnT} 8$ may play an important role in the CD147 signal transduction pathway as an upstream modulator of MMP-2 production in tumor cells. Thus, this pathway may serve as a therapeutic target in preventing tumor progression.

\section{Acknowledgements}

The present study was supported by the National Natural Science Foundation of China (no. 31170772 ) and the Suzhou Municipal Natural Science Foundation (SYS201208).

\section{References}

1. Hakomori S: Glycosylation defining cancer malignancy: new wine in an old bottle. Proc Natl Acad Sci USA 99: 10231-10233, 2002.

2. Narimatsu H: Human glycogene cloning: focus on beta 3-glycosyltransferase and beta 4-glycosyltransferase families. Curr Opin Struct Biol 16: 567-575, 2006.

3. Ishida H, Togayachi A, Sakai T, et al: A novel $\beta 1,3-N$ acetylglucosaminyltransferase ( $\beta 3 \mathrm{Gn}-\mathrm{T} 8)$, which synthesizes poly- $N$-acetyllactosamine, is dramatically upregulated in colon cancer. FEBS Lett 579: 71-78, 2005.

4. Mitsui Y, Yamada K, Hara S, Kinoshita M, Hayakawa T and Kakehi K: Comparative studies on glycoproteins expressing polylactosamine-type N-glycans in cancer cells. J Pharm Biomed Anal 70: 718-726, 2012.

5. Zamze S, Harvey DJ, Chen YJ, Guile GR, Dwek RA and Wing DR: Sialylated N-glycans in adult rat brain tissue - a widespread distribution of disialylated antennae in complex and hybrid structures. Eur J Biochem 258: 243-270, 1998.

6. Nishihara S, Iwasaki H, Kaneko M, Tawada A, Ito M and Narimatsu H: $\alpha 1,3$-fucosyltransferase 9 (FUT9; Fuc-TIX) preferentially fucosylates the distal GlcNAc residue of polylactosamine chain while the other four $\alpha 1,3$ FUT members preferentially fucosylate the inner GlcNAc residue. FEBS Lett 462: 289-294, 1999.

7. Dennis JW, Granovsky M and Warren CE: Glycoprotein glycosylation and cancer progression. Biochim Biophys Acta 1473: 21-34, 1999.

8. Yamamoto S, Oka S, Inoue M, et al: Mice deficient in nervous system-specific carbohydrate epitope HNK-1 exhibit impaired synaptic plasticity and spatial learning. J Biol Chem 277: 27227-27231, 2002.

9. Shen L, Liu Z, Tu Y, Xu L, Sun X and Wu S: Regulation of MMP-2 expression and activity by $\beta-1,3-\mathrm{N}$-acetylglucosaminyltransferase-8 in AGS gastric cancer cells. Mol Biol Rep 38: 1541-1550, 2011.

10. Gabison EE, Hoang-Xuan T, Mauviel A and Menashi S: EMMPRIN/CD147, an MMP modulator in cancer, development and tissue repair. Biochimie 87: 361-368, 2005.

11. Tang W, Chang SB and Hemler ME: Links between CD147 function, glycosylation, and caveolin-1. Mol Biol Cell 15: 4043-4050, 2004

12. Caudroy S, Polette M, Nawrocki-Raby B, et al: EMMPRINmediated MMP regulation in tumor and endothelial cells. Clin Exp Metastasis 19: 697-702, 2002.
13. Contessa JN, Bhojani MS, Freeze HH, Rehemtulla A and Lawrence TS: Inhibition of N-linked glycosylation disrupts receptor tyrosine kinase signaling in tumor cells. Cancer Res 68: 3803-3809, 2008.

14. Venkatesan B, Valente AJ, Prabhu SD, Shanmugam P, Delafontaine $\mathrm{P}$ and Chandrasekar B: EMMPRIN activates multiple transcription factors in cardiomyocytes, and induces interleukin-18 expression via Rac1-dependent PI3K/Akt/ IKK/NF-kappaB andMKK7/JNK/AP-1 signaling. J Mol Cell Cardiol 49: 655-663, 2010.

15. Yamamoto H, Swoger J, Greene S, et al: $\beta 1,6-N$-acetylglucosamine-bearing $N$-glycans in human gliomas: implications for a role in regulating invasivity. Cancer Res 60: 134-142, 2000.

16. Agrawal SM and Yong VW: The many faces of EMMPRIN-roles in neuroinflammation. Biochim Biophys Acta 1812: 213-219, 2011.

17. Fan J, Wang S, Yu S, He J, Zheng W and Zhang J: $N$-acetylglucosaminyltransferase IVa regulates metastatic potential of mouse hepatocarcinoma cells through glycosylation of CD147. Glycoconj J 29: 323-334, 2012.

18. Yu XL, Jiang JL, Li L, Feng Q, Xu J and Chen ZN: The glycosylation characteristic of hepatoma-associated antigen HAb18G/CD147 in human hepatoma cells. Int J Biochem Cell Biol 38: 1939-1945, 2006.

19. Sun J and Hemler ME: Regulation of MMP-1 and MMP-2 production through CD147/extracellular matrix metalloproteinase inducer interactions. Cancer Res 61: 2276-2281, 2001.

20. Huang W, Luo WJ, Zhu P, et al: Modulation of CD147-induced matrix metalloproteinase activity: role of CD147 N-glycosylation. Biochem J 449: 437-448, 2013.

21. Seko A and Yamashita K: Activation of $\beta 1,3-N$-acetylglucosaminyltransferase-2 ( $\beta 3 \mathrm{Gn}-\mathrm{T} 2)$ by $\beta 3 \mathrm{Gn}-\mathrm{T} 8$ : Possible involvement of $\beta 3 \mathrm{Gn}-\mathrm{T} 8$ in increasing poly-N-acetyllactosamine chains in differentiated HL-60 cells. J Biol Chem 283: 3309433100,2008

22. Huang C, Zhou J, Wu S, Shan Y, Teng S and Yu L: Cloning and tissue distribution of the human B3GALT7 gene, a member of the beta1,3-glycosyltransferase family. Glycoconj J 21: 267-273, 2004.

23. Saitoh O, Wang WC, Lotan R and Fukuda M: Differential glycosylation and cell surface expression of lysosomal membrane glycoproteins in sublines of a human colon cancer exhibiting distinct metastatic potentials. J Biol Chem 267: 5700-5711, 1992.

24. Taniguchi N, Miyoshi E, Ko JH, Ikeda Y and Ihara Y: Implication of N-acetylglucosaminyltransferases III and $\mathrm{V}$ in cancer: gene regulation and signaling mechanism. Biochim Biophys Acta 1455: 287-300, 1999.

25. Togayachi A, Akashima T, Ookubo R, et al: Molecular cloning and characterization of UDP-GlcNAc:lactosylceramide beta 1,3-N-acetylglucosaminyltransferase (beta 3Gn-T5), an essential enzyme for the expression of HNK-1 and Lewis X epitopes on glycolipids. J Biol Chem 276: 22032-22040, 2001.

26. Shiraishi N, Natsume A, Togayachi A, et al: Identification and characterization of three novel $\beta \quad 1,3-N$-acetylglucosaminyltransferases structurally related to the $\beta 1,3$-galactosyltransferase family. J Biol Chem 276: 3498-3507, 2001.

27. Dennis JW, Laferte S and Vanderelst I: Asparagine-linked oligosaccharides in malignant tumour growth. Biochem Soc Trans 17: 29-31, 1989.

28. Dennis JW and Laferte S: Oncodevelopmental expression of -GlcNAc $\beta 1-6$ Man $\alpha$ 1-6Man $\beta 1$-branched asparagine-linked oligosaccharides in murine tissues and human breast carcinomas. Cancer Res 49: 945-950, 1989.

29. Seberger PJ and Chaney WG: Control of metastasis by Asn-linked, $\beta$-6-branched oligosaccharides in mouse mammary cancer cells. Glycobiology 9: 235-241, 1999.

30. Granovsky M, Fata J, Pawling J, Muller WJ, Khokha R and Dennis JW: Suppression of tumor growth and metastasis in Mgat5-deficient mice. Nat Med 6: 306-312, 2000.

31. Del Grosso F, De Mariano M, Passoni L, Luksch R, Tonini GP and Longo L: Inhibition of N-linked glycosylation impairs ALK phosphorylation and disrupts pro-survival signaling in neuroblastoma cell lines. BMC Cancer 11: 525, 2011. 